\title{
Correction to: Work Transitions, Gender, and Subjective Well-Being
}

\section{Hye Yoon Chung ${ }^{1}$ (I) $\cdot$ Youjin Hahn ${ }^{1}$}

Published online: 16 October 2020

(C) The International Society for Quality-of-Life Studies (ISQOLS) and Springer Nature B.V. 2020

\section{Correction to: Applied Research in Quality of Life https://doi.org/10.1007/s11482-020-09860-z}

The original version of the article contained a formatting error in Tables 1-3, 5, 11, and 13 that could be misleading.

The original article has been corrected.

Publisher's Note Springer Nature remains neutral with regard to jurisdictional claims in published maps and institutional affiliations.

The online version of the original article can be found at https://doi.org/10.1007/s11482-020-09860-z

Youjin Hahn

youjin.hahn@yonsei.ac.kr

Hye Yoon Chung

h.chung@yonsei.ac.kr

1 School of Economics, Yonsei University, Seoul, Republic of Korea 